\title{
Assembly of the Tc1 and mariner transposition initiation complexes depends on the origins of their transposase DNA binding domains
}

Benjamin Brillet · Yves Bigot · Corinne Augé-Gouillou

Published online: 29 June 2007

(C) Springer Science+Business Media B.V. 2007

Erratum to: Genetica (2007) 130: 105-120

DOI 10.1007/s10709-006-0025-2

This erratum is being published as a result of author's first

$\&$ last names were interchanged.

Author names should be now read as:

Benjamin Brillet, Yves Bigot, Corinne Augé-Gouillou

The online version of the original article can be found under doi: 10.1007/s10709-006-0025-2.

B. Brillet · Y. Bigot · C. Augé-Gouillou ( $\square)$ Laboratoire d'Etudes des Parasites Génétiques, Université François Rabelais, FRE CNRS 2969, UFR Sciences \& Techniques, Parc Grandmont, 37200 Tours, France e-mail: auge@univ-tours.fr 